\title{
Prognostic significance of L-type amino acid transporter I expression in resectable stage I-III nonsmall cell lung cancer
}

\section{K Kaira,', N Oriuchi' ${ }^{2}$ H Imai', K Shimizu ${ }^{3}$ N Yanagitani', N Sunaga', T Hisada', S Tanaka ${ }^{4}$, T Ishizuka', Y Kanai ${ }^{5}, \mathrm{H}$ Endou $^{6}$, T Nakajima ${ }^{7}$ and M Mori $^{1}$}

'Department of Medicine and Molecular Science, Gunma University Graduate School of Medicine, Showa-machi, Maebashi, Gunma 37 I-85 I I, Japan; ${ }^{2}$ Department of Diagnostic Radiology and Nuclear medicine, Gunma University Graduate School of Medicine, Showa-machi, Maebashi, Gunma 37 I-85 I I, Japan; ${ }^{3}$ Department of Thoracic and Visceral Organ Surgery, Gunma University Graduate School of Medicine, Showa-machi, Maebashi, Gunma 37 I-85 II, Japan; ${ }^{4}$ Department of General Surgical Science, Gunma University Graduate School of Medicine, Showa-machi, Maebashi, Gunma 37 I-85 I I, Japan; ${ }^{5}$ Division of Bio-system Pharmacology, Graduate School of Medicine, Osaka University, Suita, Osaka 565-087, Japan; ${ }^{6}$ Department of Pharmacology and Toxicology, Kyorin University School of Medicine, Shinkawa, Mitaka, Tokyo I81-86 II, Japan; ${ }^{7}$ Department of Tumour Pathology, Gunma University Graduate School of Medicine, Showa-machi, Maebashi, Gunma 37I-85 II, Japan

The clinical significance of L-type amino acid transporter I (LATI) expression remains unclear, whereas many experimental studies have demonstrated that LATI is associated with the proliferation of cancer cells. The purpose of this study was to evaluate the prognostic value of LATI in patients with nonsmall cell lung cancer (NSCLC). A total of 32I consecutive patients with completely resected pathologic stage I-III NSCLC were retrospectively reviewed. Expression of LATI and proliferative activity, as determined by the Ki-67 labelling index, was also evaluated immunohistochemically and correlated with the prognosis of patients who underwent complete resection of the tumour. Expression of LATI was positive in 163 patients (51\%) (29\% of adenocaricnoma (58 of 200 patients), $91 \%$ of squamous cell carcinoma (9I of 100 patients), and $67 \%$ of large cell carcinoma ( 14 of 21 patients)). The 5 -year survival rate of LATI-positive patients (5I.8\%) was significantly worse than that of LATI-negative patients $(87.8 \%$; $P<0.00$ I). L-type amino acid transporter I expression was significantly associated with lymph node metastasis and disease stage. Multivariate analysis confirmed that positive expression of LATI was an independent factor for predicting a poor prognosis. There was a significant correlation between LATI expression and Ki-67 labelling index. LATI expression is a promising pathological factor to predict the prognosis in patients with resectable stage I-III NSCLC.

British Journal of Cancer (2008) 98, 742-748. doi:10.1038/sj.bjc.6604235 www.bjcancer.com

Published online 5 February 2008

(c) 2008 Cancer Research UK

Keywords: LATI; nonsmall cell lung cancer; amino acid transporter; prognostic factor; Ki-67

Nonsmall cell lung cancer (NSCLC) is the leading cause of cancer death and has a poor prognosis (Shottenfeld, 1996). To improve the prognosis of patients, clinical markers that may predict the prognosis and response to the specific therapy should be established. Tumour staging and performance status have been consistently shown to be the most powerful prognostic tool for survival rates of NSCLC patients (Brundage et al, 2002). The prognostic factors such as ' $\mathrm{N}$ ' factor, tumour size, sex, and vessel invasion have been shown to determine overall outcome in patients with surgically resected NSCLC (Brundage et al, 2002). Recently, excision repair cross-complementation group 1 has been described to be a new promising marker for drug response and overall survival in NSCLC patients (Olaussen et al, 2006). However, there has been no established clinical marker, which correlates with the response to the treatment and the prognosis in patients with NSCLC (Clinical practice guidelines for the treatment of unresectable nonsmall cell lung cancer, 1997).

*Correspondence: Dr K Kaira; E-mail: kkaira1970@yahoo.co.jp Received 30 August 2007; revised 4 January 2008; accepted 9 January 2008; published online 5 February 2008
Amino acid transporters are essential for growth and proliferation in normal and transformed cells (Christensen, 1990; McGivan and Pastor-Anglada, 1994). Among amino acid transporters, system $\mathrm{L}$ is a $\mathrm{Na}^{+}$-independent large and neutral amino acid transport agency (Oxender and Christensen, 1962; Christensen, 1990). L-type amino acid transporter 1 (LAT1) is one of the L-type amino acid transporters, and transports large neutral amino acids such as leucine, isoleucine, valine, phenylalanine, tyrosine, tryptophan, methionine and histidine (Oxender and Christensen, 1962; Kanai et al, 1998; Yanagida et al, 2001). L-type amino acid transporter 1 requires covalent association with the heavy chain of $4 \mathrm{~F} 2$ cell surface antigen ( $4 \mathrm{~F} 2 \mathrm{hc}$ ) for its functional expression in plasma membrane (Oxender and Christensen, 1962). Previous studies have shown LAT1 to be highly expressed in proliferating tissues, many tumour cell lines (T24 bladder carcinoma cells, RERF-LC-MA lung small-cell carcinoma cells, and HeLa uterine cervical carcinoma cells) and primary human tumours (Yanagida et al, 2001). It has been reported that LAT1 expression is closely related to tumour cell growth of liver metastases in a rat model (Ohkame et al, 2001). Recent studies demonstrated the overexpression of LAT1 in pulmonary adenocarcinoma and oesophageal carcinoma (Kobayashi et al, 2005; Nakanishi et al, 2006). High LAT1 immunostaining was described to predict a poor prognosis 
in patients with astrocytic brain tumours (Nawashiro et al, 2006). The RNA interference to downregulate LAT1 has been described to impair the proliferation of human oral cancer cells (Kim et al, 2006). Although many experimental studies have clearly indicated that LAT1 is associated with cancerous or proliferative cells, the clinical significance of LAT1 expression in NSCLC remains unclear (Yanagida et al, 2001; Nakanishi et al, 2006). Since there is no clinical study on LAT1 expression in NSCLC, the correlation between LAT1 expression and prognosis is also unknown. In this study, therefore, the pathological findings including LAT1 expression was assessed in the resected tissue specimen and correlated with clinical feature and outcome. In addition, LAT1 expression was correlated with the proliferative activity of the tumour as assessed by the Ki-67 labelling index.

\section{MATERIALS AND METHODS}

\section{Patients}

We analysed 361 consecutive patients with NSCLC who underwent resection either by lobectomy or pneumonectomy with mediastinal lymph node dissection at Gunma University Hospital between June 1998 and May 2004. Nineteen patients who received induction of chemotherapy or radiation therapy and one patient who suffered from an operation-related death were excluded. Specimens of 20 patients were not available. A total of 321 patients (196 men, 125 women) were evaluated. The study protocol was approved by the institutional review board.

The age of the patients ranged from 39 to 84 years, and the mean age at the time of surgery was 67 years. The tumour specimens were histologically classified according to the criteria of the World Health Organization. Postsurgical pathologic stage was determined by the current tumour-node-metastasis classification (Mountain, 1997). Histologically, 200 patients had adenocarcinoma, 100 had squamous cell carcinoma (SQC), and 21 had large cell carcinoma (LCC). Of the total patients, 241, 28 and 52 had stage I, II and III tumours, respectively. As postoperative adjuvant therapies, platinum-based chemotherapy, radiation, and oral administration of tegafur (a fluorouracil derivative drug) were administered to 27, 14 , and 35 patients, respectively. Intraoperative therapy was not performed on any patient. The postoperative clinical course was assessed by analysing outpatient medical records and by marking telephone inquiries. The day of surgery was considered the starting day for counting postoperative survival. The follow-up duration ranged from 6 to 86 months (median, 48 months).

\section{Immunohistochemical staining with LAT1 and Ki-67}

LAT1 L-type amino acid transporter 1 expression was determined by immunohistochemical staining with an affinity-purified polyclonal rabbit anti-human LAT1 antibody (Yanagida et al, 2001). An oligopeptide corresponding to amino acid residues $497-$ 507 of human LAT1 (CQKLMQVVPQET) was synthesized. The Nterminal cysteine residue was introduced for conjugation with keyhole limpet hemocyanine. Antipeptide antibody was produced as described elsewhere (Chairoungdua et al, 1999). For immunohistochemical analysis, antiserum was affinity-purified as described previously (Chairoungdua et al, 1999).

Immunohistochemical staining was performed on paraffin sections using a polymer peroxidase method (Envision + /HRP; Dako Cytomation CO., Ltd., Denmark). Briefly, deparaffinised and rehydrated sections were treated with $0.3 \%$ hydrogen peroxide in methanol for $30 \mathrm{~min}$ to block endogenous peroxidase activity. To expose antigens, sections were autoclaved in $10 \mathrm{mmoll}^{-1}$ sodium citrate buffer ( $\mathrm{pH}$ 6.0) for $5 \mathrm{~min}$, and cooled for $30 \mathrm{~min}$. After rinsing in $0.05 \mathrm{M}$ tris-buffered saline containing $0.1 \%$ tween 20 , the sections were incubated with affinity-purified anti-LAT1 antibody $\left(1.2 \mathrm{mg} \mathrm{ml}^{-1} ; 1: 3200\right)$ overnight at $4^{\circ} \mathrm{C}$. Thereafter, they were incubated with Envision $(+)$ rabbit peroxidase (Dako, Carpinteria, CA, USA) for $30 \mathrm{~min}$. The peroxidase reaction was performed using $0.02 \% 3,3^{\prime}$-diaminobenzidine tetrahydrochloride and $0.01 \%$ hydrogen peroxide in $0.05 \mathrm{M}$ tris $-\mathrm{HCl}$ buffer, $\mathrm{pH}$ 7.4. Finally, nuclear counterstaining was performed with Mayer's hematoxylin. For negative control, incubation step with the primary antibody was omitted. The specificity of immunoreactions using the antiLAT1 antibody was established in previous studies (Matsuo et al, 2000; Nawashiro et al, 2006).

LAT1 expression was considered positive only if distinct membrane staining was present. Staining intensity was scored as follows: (1) $<10 \%$ of tumour area stained; (2) $11-25 \%$ stained; (3) $26-50 \%$ stained; and $(4) \geqslant 51 \%$ stained. The tumours in which stained tumour cells made up more than $10 \%$ of the tumour were graded as positive. According to this scoring protocol, two investigators from the authors, without prior knowledge of the clinical data, independently graded the staining intensity in all cases. To test the intraobserver variability, each section was reassessed by the same investigators after the first assessment had been completed. The time interval between the first and second assessments was at least 4 weeks. The interobserver variability was also determined by comparing the values of the first measurements of two investigators.

Ki-67 The detailed protocol for immunostaining was published elsewhere (Buck et al, 2001). Briefly, formalin-fixed and paraffinembedded sections of resected specimens were dewaxed, rehydrated, trypsinized, and boiled in $0.01 \mathrm{~mol} / \mathrm{l}$. citrate buffer for $30 \mathrm{~min}$. For immunostaining, the monoclonal mouse antibody MIB-1 (Dako, Denmark), specific for human nuclear antigen Ki-67, was used in a $1: 40$ dilution. The sections were lightly counterstained with hematoxylin. As a positive control for proliferating cells, sections of tonsil were used.

A highly cellular area of the immunostained sections was evaluated. All epithelial cells with nuclear staining of any intensity were defined as positive. Approximately 1000 nuclei were counted on each slide. Proliferative activity was assessed as the percentage of MIB-1-stained nuclei in the sample. Ki-67 expression was defined as low if less than $25 \%$ of tumour cells showed staining in nuclei in a tumour section. This definition was used according to the commonly used cutoff values ranging from 20 to $40 \%$ in NSCLC and other human cancers in the current literature (Martin et al, 2004) and also based on the examination of our staining data. Sections were evaluated by two investigators separately and in case of discrepancies both would evaluate the slide simultaneously and would agree in their final assessment. Neither investigators had knowledge of patient outcome.

\section{Statistical analysis}

The $\chi^{2}$-test and Fisher's exact test was used to examine the association of two categorical variables. Correlations between LAT1 expression and Ki-67 labelling index were analysed by using the nonparametric Spearman's rank test.

Survival time was determined as the time from tumour resection to death from any cause. For survivors, survival times were censored on the last date that patients were known to be alive. The Kaplan-Meier method was used to estimate survival as a function of time, and survival differences were analysed by the log-rank test. Multivariate analyses were performed using stepwise Cox proportional hazards model to identify independent prognostic factors. A $P$-value less than 0.05 was considered indicative of statistical significance. Statistical analysis was performed using StatView J-4.5 for Macintosh. 


\section{RESULTS}

\section{Expression of LAT1 in NSCLC}

L-type amino acid transporter 1 immunostaining was detected in carcinoma cells in tumour tissues and localised predominantly on their plasma membrane (Figure 1). In the present study, no expression of LAT1 protein was observed in any normal epithelial cells of the lung, including bronchial epithelial and alveolar cells. All positive cells revealed strong membranous LAT1 immunostaining. It is worthy to note that the staining intensity of the cell membrane and the percentage of positive cells were considerably greater in SQC and LCC than AC. The cytoplasmic staining was rarely evident. Expression of LAT1 was positive in 51\% (163 of 321 patients) (29\% of AC (58 of 200 patients), 91\% of SQC (91 of 100 patients), and $67 \%$ of LCC (14 of 21 patients)). The incidence of a positive LAT1 expression was significantly different between AC and SQC $(P<0.001)$ and between AC and non-AC $(P<0.001)$. The average score of the LAT1 expression was $2.0 \pm 1.2$ on a scale of $1-4$. The LAT1 score was $1.5 \pm 0.8$ in AC, $3.1 \pm 1.0$ in SQC and $2.5 \pm 1.3$ in LCC. There was a significant difference in the LAT1 score between AC and SQC $(P<0.001)$ and between AC and LCC $(P<0.001)$.

Expression of LAT1 according to patient's characteristics is listed in Table 1. In NSCLC, LAT1 expression was significantly associated with gender, tumour size, lymph node metastasis, disease stage, lymphatic permeation, vascular permeation, and pleural involvement. In AC, LAT1 expression was significantly associated with gender, lymph node metastasis, disease stage, lymphatic permeation, vascular permeation, and pleural involvement. In SQC, LAT1 expression was significantly associated with lymph node metastasis.

\section{LAT1 expression and postoperative survival}

Postoperative survival according to LAT1 status is listed in Table 2. For all patients, the 5-year survival rates of the LAT1-positive and LAT1-negative patients were 51.8 and $87.8 \%$, respectively, demonstrating a significantly poor prognosis for LAT1-positive patients $(P<0.001$, Figure $2 \mathrm{~A}, \mathrm{~B}$ and $\mathrm{C})$. Postoperative survival was also analysed by age, gender, and pathologic stage. For pathologic stage I disease, the 5-year survival rates of LAT1-positive and LAT1-negative patients were 67.9 and $90.9 \%$, respectively, demonstrating a significantly poor prognosis for the LAT1-positive patients $(P<0.001$, Table 2$)$. For pathologic stage II and III disease, the 5-year survival rates of LAT1-positive and LAT1-negative patients were 25.6 and $68.3 \%$, respectively, demonstrating a significantly poor prognosis for the LAT1-positive patients $(P=0.021$, Table 2). A significant difference in the prognosis between the LAT1-positive and LAT1-negative patients was also demonstrated for age and gender (Table 2).

\section{LAT1 and Ki-67 expression}

The Ki-67 labelling index averaged $35 \pm 24 \%$ (median, $32 \%$ ) and ranged from 5 to $92 \%$ in NSCLC. The Ki-67 labelling index was $23 \pm 20 \%$ (median, $18 \%$ ) in AC, $54 \pm 17 \%$ (median, $56 \%$ ) in SQC
A



C

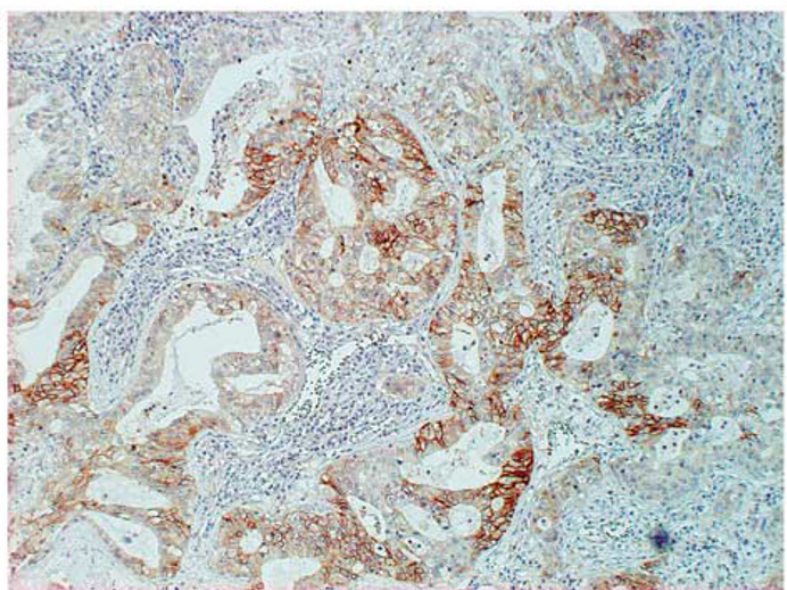

B



D



Figure I Immunohistochemical analysis of LATI in NSCLC. (A) Positive staining of LATI expression in squamous cell carcinoma. The score of LATI immunostaining was grade 4 and its immunostaining pattern was membranous. (B) LATI expression in squamous cell carcinoma with staining score of grade 2. (C) LATI expression in adenocarcinoma with staining score of grade 3. (D) LATI expression in large cell carcinoma with staining score of grade 4. 


\begin{tabular}{|c|c|c|c|c|c|c|c|c|c|}
\hline \multirow[b]{3}{*}{ Parameter } & \multicolumn{3}{|c|}{$\mathbf{A l l}^{\mathbf{a}}$} & \multicolumn{3}{|c|}{ Adenocarcinoma } & \multicolumn{3}{|c|}{ Squamous cell carcinoma } \\
\hline & \multirow[b]{2}{*}{ No. } & \multicolumn{2}{|c|}{ LAT I positive } & \multirow[b]{2}{*}{ No. } & \multicolumn{2}{|c|}{ LAT I positive } & \multirow[b]{2}{*}{ No. } & \multicolumn{2}{|c|}{ LATI positive } \\
\hline & & No. (\%) & $P$-value & & No. (\%) & $P$-value & & No. (\%) & $P$-value \\
\hline Total & 321 & $163(5 \mid)$ & & 200 & $58(29)$ & & 100 & $91(91)$ & \\
\hline \multicolumn{10}{|l|}{ Age } \\
\hline$\leqslant 65$ years & 105 & $45(43)$ & 0.186 & 77 & $20(26)$ & 0.280 & 20 & $18(90)$ & 0.74 \\
\hline$>65$ years & 216 & $118(55)$ & & 123 & $38(31)$ & & 80 & $73(91)$ & \\
\hline \multicolumn{10}{|l|}{ Gender } \\
\hline Male & 205 & |3| (64) & $<0.001^{b}$ & 94 & $34(36)$ & 0.025 & 92 & $83(90)$ & 0.456 \\
\hline Female & 116 & $32(28)$ & & 106 & $24(23)$ & & 8 & $8(100)$ & \\
\hline \multicolumn{10}{|c|}{ Tumour size (mm) } \\
\hline$\leqslant 30$ & 159 & $84(53)$ & 0.022 & 108 & $38(35)$ & 0.738 & 47 & 42 (89) & 0.423 \\
\hline$>30$ & 124 & $81(65)$ & & 54 & $21(39)$ & & 53 & $49(92)$ & \\
\hline \multicolumn{10}{|c|}{ Lymph node metastasis } \\
\hline Positive & 56 & $39(70)$ & $<0.001$ & 30 & $16(52)$ & $<0.001$ & 18 & $18(100)$ & $<0.001$ \\
\hline Negative & 265 & $24(9)$ & & 170 & $14(8)$ & & 82 & $0(0)$ & \\
\hline \multicolumn{10}{|c|}{ Disease stage ( $p$-stage) } \\
\hline 1 & 241 & $104(43)$ & $<0.001$ & 164 & 38 (23) & $<0.001$ & 69 & 61 (88) & 0.59 \\
\hline$\|+\| \|$ & 80 & $61(76)$ & & 36 & $21(58)$ & & 15 & | 4 (93) & \\
\hline \multicolumn{10}{|c|}{ Lymphatic permeation } \\
\hline Positive & 126 & $87(69)$ & $<0.001$ & 65 & 31 (48) & $<0.001$ & 51 & $46(90)$ & 0.526 \\
\hline Negative & 194 & 77 (40) & & 135 & $27(20)$ & & 49 & $45(92)$ & \\
\hline \multicolumn{10}{|c|}{ Vascular invasion } \\
\hline Positive & 94 & $64(68)$ & $<0.001$ & 45 & $19(42)$ & 0.022 & 40 & $36(90)$ & 0.74 \\
\hline Negative & 227 & $100(44)$ & & 155 & $39(25)$ & & 60 & $55(92)$ & \\
\hline \multicolumn{10}{|c|}{ Pleural involvement } \\
\hline Positive & 103 & $66(64)$ & $<0.001$ & 55 & $25(45)$ & $<0.001$ & 34 & $30(88)$ & 0.855 \\
\hline Negative & 219 & $98(45)$ & & 145 & 33 (23) & & 66 & 61 (92) & \\
\hline
\end{tabular}

LATI = L-type amino acid transporter I. a Large cell carcinoma was included. ${ }^{\mathrm{b}}$ Statistically significant.

Table 2 Five-year survival according to LATI expression

\begin{tabular}{lccr}
\hline & \multicolumn{3}{c}{ Five-year survival rate (\%) } \\
\cline { 2 - 4 } Variable & LATI positive & LATI negative & P-value $^{\mathbf{b}}$ \\
\hline All patients & 51.8 & 87.8 & $<0.001$ \\
Age & & & \\
$\quad \leqslant 65$ years & 60.0 & 90.0 & 0.008 \\
$>65$ years & 46.9 & 83.1 & $<0.001$ \\
Gender & & & \\
$\quad$ Male & 47.7 & 79.3 & 0.006 \\
Female & 63.9 & 98.2 & $<0.001$ \\
Pathologic stage & & & $<0.001$ \\
I & 67.9 & 90.9 & 0.021 \\
II+III & 25.6 & 68.3 & \\
\hline
\end{tabular}

LATI = L-type amino acid transporter I. ${ }^{a}$ Kaplan-Meier analysis. ${ }^{b}$ Log-rank test.

and $56 \pm 21 \%$ (median, $63 \%$ ) in LCC. The Ki-67 labelling index was significantly different between AC and SQC $(P<0.001)$ and between AC and LCC $(P<0.001)$.

Significant correlation was found between LAT1 expression and Ki-67 labelling index (Spearman's rank correlation coefficient $\gamma=0.772, P<0.001)$ in NSCLC $($ AC $(\gamma=0.5817, P<0.001)$, SQC $(\gamma=0.6917, P<0.001)$, and (LCC $(\gamma=0.7947, P<0.001))$ (Figure 3$)$. Moreover, Kaplan-Meier analysis demonstrated that 5-year survival rate of patients with high Ki-67 labelling index tumours significantly decreased in comparison with those with low Ki-67 labelling index tumours (57.5 vs $89.2 \%$; $P<0.001)$ (Figure 2D).

\section{Multivariate analysis of prognostic factors}

Multivariate analysis confirmed that positive expression of LAT1 was an independent and significant factor to predict a poor prognosis. Pathologic stage was also a significant prognostic factor (Table 3).

\section{DISCUSSION}

The present study evaluated the clinical significance of LAT1 expression in NSCLC. The results of the study clearly demonstrated that the expression of LAT1, and the pathologic disease stage, was a significant independent factor to predict a poor prognosis in patients with completely resected NSCLC. Moreover, our study has shown that LAT1 expression was significantly associated with lymph node metastasis and disease stage.

It is widely known that amino acid transport systems play an important role in the regulation of cellular proliferation, whereas the details of its function to promote tumour cell proliferation have not been clarified (Kanai et al, 1998). Full-length LAT1 was 

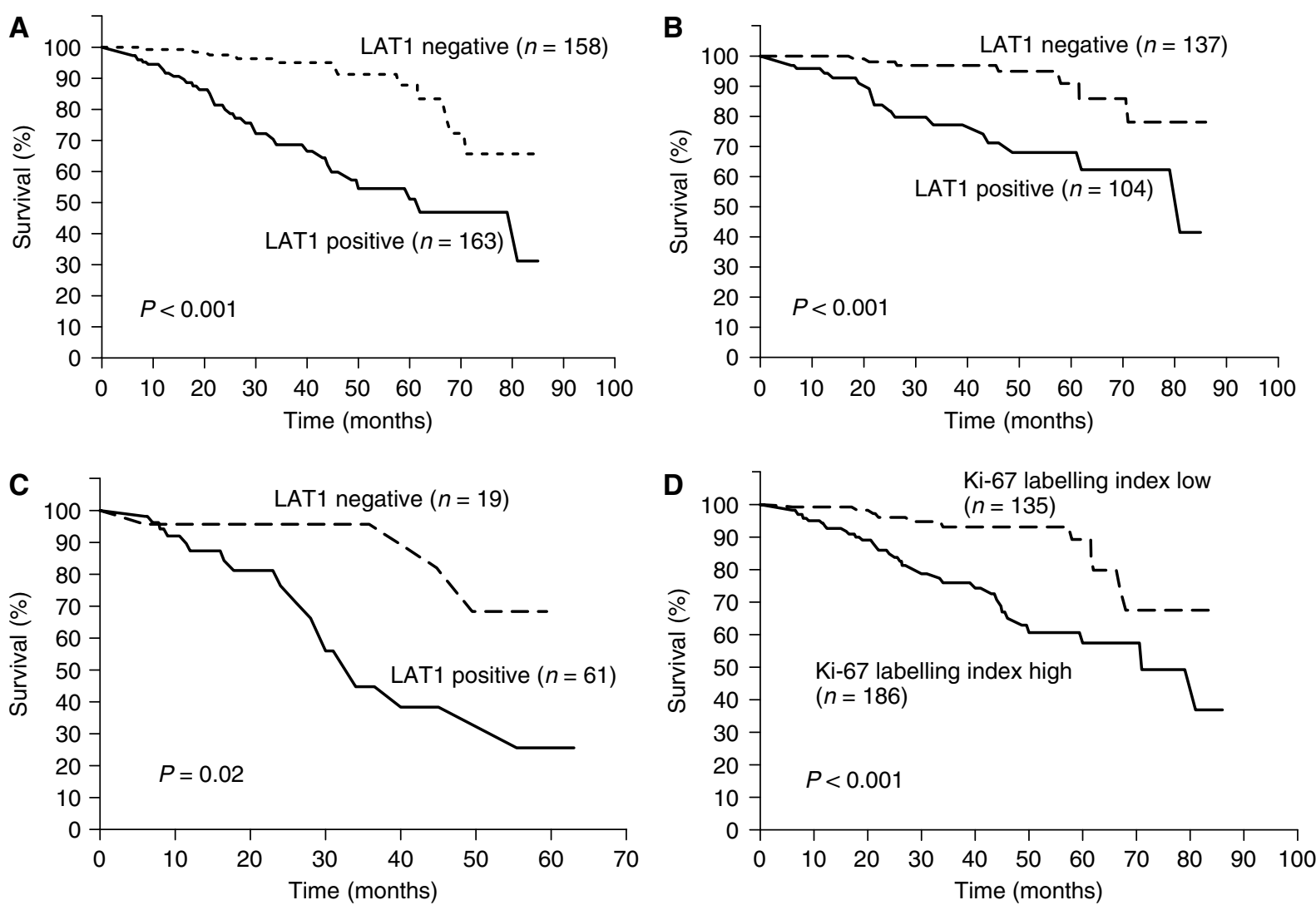

Figure 2 Postoperative survival of patients with completely resected pathologic stage I-III non-small cell lung cancer. Comparison of postoperative survival rates were based on LATI expression and Ki-67 labelling index. The survival rate of LATI-positive patients was significantly worse than that of LATI-negative patients with stage I-III NSCLC $(P<0.00 I)(\mathbf{A})$. The survival rate of LATI-positive patients was also associated with an unfavourable prognosis in stage I $(P<0.00 I)(\mathbf{B})$ and stage II + III NSCLC $(P=0.02)(\mathbf{C})$. The survival rate of patients with high Ki-67 labelling index was significantly worse than that with low Ki-67 labelling index $(P<0.00$ I) $(\mathbf{D})$.

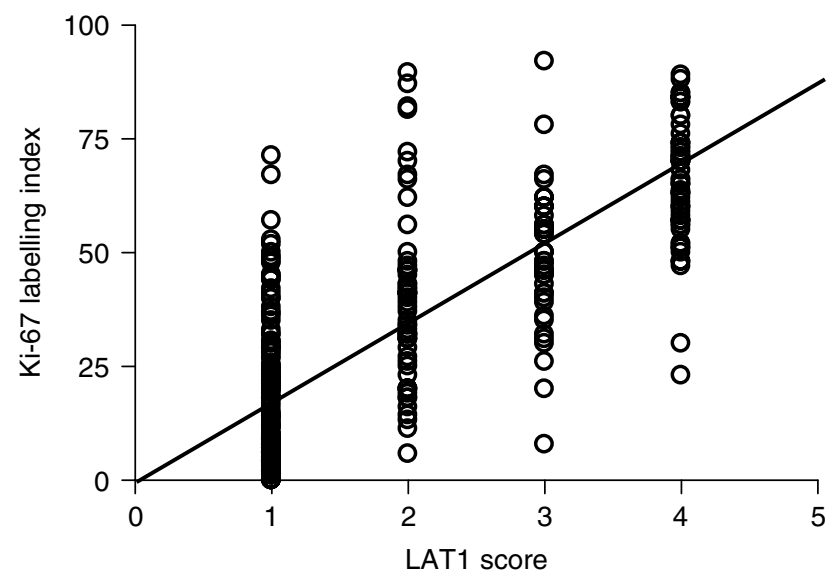

Figure 3 Correlation of LATI expression with Ki-67 labelling index $(\gamma=0.772, P<0.00 I)$.

first isolated and characterised in 1998 (Kanai et al, 1998). LAT1 is widely expressed in primary human cancers and several cancer cell lines, where it has been shown to play essential roles in growth and survival (Fuchs and Bode, 2006). While it is currently unclear why LAT1 is coveted by transformed cell, Fuchs et al hypothesize that LAT1 provides the essential amino acids that act as signal to enhance growth of cancer cells via mammalian target-of-rapamycin (mTOR)-stimulated translation (Fuchs and Bode, 2006). Likewise,
mTOR regulates amino acid transporter gene expression and trafficking to the plasma membrane in response to the growth signal (Fuchs and Bode, 2006). Moreover, overexpression of LAT1 was described to be associated with metastasis in vivo (Ohkame et al, 2001; Tamai et al, 2001). When colon cancer RCN-9 cells were injected into the spleen of rats, the size of the resultant metastatic liver tumours was directly correlated to LAT1 expression (Ohkame et al, 2001; Tamai et al, 2001). Thus, inhibition of LAT1 function could be a potential therapeutic strategy for many types of cancer (Kanai and Endou, 2001; Fuchs and Bode, 2006). Whereas, LAT1 has been shown to mediate the uptake of a number of amino acidrelated compounds such as L-dopa, triiodothyronine, thyroxin, and the anti-cancer agent melphalan (L-phenylalanine mustard, L-PAM, Alkeran, L-Sarcolysin) (Uchino et al, 2002). LAT1 appears to have opposing roles for the growth of cancer cell and also the suppression of the growth. It is a potential target per se because it supplies tumour cells with essential amino acids necessary for protein synthesis and cell growth. Conversely, its upregulation in a variety of cancers might be exploited for anti-tumour drugs like melphalan.

L-type amino acid transporter 1 protein overexpression in bronchioalveolar carcinoma is shown to associate with the Ki-67 labelling index, indicating an upregulation of metabolic activity (Nakanishi et al, 2006). Our result revealed that Ki-67 labelling index is significantly correlated with LAT1 expression in NSCLC. Ki-67 labelling index in SQC and LCC was significantly higher than that in AC. A meta-analysis indicated that the expression of Ki-67 is a factor of poor prognosis for survival in NSCLC (Martin et al, 2004). The present study revealed that high Ki-67 labelling index is 
Table 3 Multivariate analysis of the prognostic factors

\begin{tabular}{lcc}
\hline Prognostic factor & Hazard ratio & 95\% confidence interval \\
\hline Age ( $\leqslant 65$ years/ $>65$ years) & 0.597 & $0.299-1.194$ \\
Gender (male/female) & 1.398 & $0.658-2.972$ \\
Histology (adenocarcinoma/squamous cell carcinoma) & 1.228 & $0.535-2.816$ \\
Disease stage (I/IIIII) & 3.544 & $1.788-7.026$ \\
LATI (positive/negative) & 3.243 & $1.356-7.755$ \\
& & 0.1447 \\
Postoperative adjuvant therapy & 0.3839 \\
Cisplatin-based intravenous chemotherapy (no/yes) & 1.135 & 0.6277 \\
Radiation therapy (no/yes) & 1.320 & $0.287-2.431$ \\
Oral administration of tegafur (no/yes) & 0.667 & $0.316-4.078$ \\
Ki-67 labeling index (low/high) & $0.562-3.101$ \\
\hline
\end{tabular}

LATI = L-type amino acid transporter I. Note: Hazard ratios, 95\% confidence intervals, and two-side P-values were obtained from the Cox proportional hazards models.

associated with an unfavourable prognosis in patients with completely resected NSCLC.

We examined LAT1 expression immunohistochemically and found that LAT1 expression in SQC and LCC was significantly higher than that in AC. Since the LAT1 expression was significantly correlated with Ki-67 labelling index, the incidence of LAT1 expression in NSCLC may be associated with tumour cell proliferation. However, the reason why the incidence of LAT1 expression was different among the histopathologic subtypes is not known and remained to be elucidated.

Several clinical investigations demonstrated the increased uptake of radiolabelled amino acids in human neoplasms (Inoue et al, 2001; Oriuchi et al, 2006; Kaira et al, 2007b). We have developed $\mathrm{L}-\left[3-{ }^{18} \mathrm{~F}\right]-\alpha-$ methyltyrosine (FMT) as a tracer for amino acid transport using positron emission tomography (PET) imaging (Tomiyoshi et al, 1997), and investigated the clinical utility of FMT in several tumours including brain tumour, lung cancer, head and neck cancer, and lymphoma (Oriuchi et al, 2006). FMT is transported via L-type amino acid transporter, which is specific

\section{REFERENCES}

Brundage MD, Davies D, Mackillop WJ (2002) Prognostic factors in non-small cell lung cancer: a decade of prognosis. Chest 122: $1037-$ 1057

Buck AC, Schirrmeister HH, Guhlmann CA, Diederichs CG, Shen C, Buchmann I, Kotzerke J, Birk D, Mattfeldt T, Reske SN (2001) Ki-67 immunostaining in pancreatic cancer and chronic active pancreatitis: does in vivo FDG uptake correlate with proliferative activity? J $\mathrm{Nucl} \mathrm{Med}$ 42: $721-725$

Chairoungdua A, Segawa H, Kim JY, Miyamoto K, Haga H, Fukui Y, Mizoguchi K, Ito H, Takeda E, Endou H, Kanai Y (1999) Identification of an amino acid transporter associated with the cystinuria-related type II membrane glycoprotein. J Biol Chem 274: 28845-28848

Christensen HN (1990) Role of amino acid transport and countertransport in nutrition and metabolism. Physiol Rev 70: 43-77

Clinical Practice Guidelines for the Treatment of Unresectable Non-Small Cell Lung Cancer (1997) Adopted on May 16, 1997 by the American Society of Clinical Oncology. J Clin Oncol 15: 2996-3018

Fuchs BC, Bode BP (2006) Amino acid transporters ASCT2 and LAT1 in cancer: partners in crime? Semin Cancer Biol 15: 254-266

Inoue T, Koyama K, Oriuchi N, Alyafei S, Yuan Z, Suzuki H, Takeuchi K, Tomaru Y, Tomiyoshi K, Aoki J, Endo K (2001) Detection of malignant tumors: whole-body PET with fluorine $18 \alpha$-methyl tyrosine $v s$ FDGpreliminary study. Radiology 220: $54-62$

Kaira K, Oriuchi N, Otani Y, Shimizu K, Tanaka S, Imai H, Yanagitani N, Sunaga N, Hisada T, Ishizuka T, Dobashi K, Kanai Y, Endou H, Nakajima T, Endo K, Mori M (2007a) Fluorine-18- $\alpha$-methyltyrosine positron emission tomography for diagnosis and staging of lung cancer: A Clinicopathological Study. Clin Cancer Res 13: 6369-6378

Kaira K, Oriuchi N, Otani Y, Yanagitani N, Sunaga N, Hisada T, Ishizuka T, Endo K, Mori M (2007b) Diagnostic usefulness of fluorine-18- $\alpha$ - to cancer cells (Kim et al, 2002; Oriuchi et al, 2006; Kaira et al, 2007b). Recently, we reported a significant correlation between FMT uptake and LAT1 expression in NSCLC (Kaira et al, 2007a).

In conclusion, positive expression of LAT1 is a significant factor to predict poor prognosis, and it may be an important clinical marker of therapy for NSCLC. LAT1 expression was significantly correlated with tumour cell proliferation. Inhibiting LAT1 function may cause a cessation of the growth of tumour and provide new and effective therapeutic target of NSCLC in the future.

\section{ACKNOWLEDGEMENTS}

We thank T Hikino and $\mathrm{F}$ Hara for technical assistance in the immunohistochemical stain of LAT1 and Ki-67.

\section{Conflict of interest}

We have no financial or personal relationships with other people or organisations that could inappropriately influence our work. methyltyrosine positron emission tomography in combination with ${ }^{18} \mathrm{~F}$-fluorodeoxyglucose in sarcoidosis patients. Chest 131: 1019-1027

Kanai Y, Endou H (2001) Heterodimeric amino acid transporters: molecular biology and pathological and pharmacological relevance. Curr Drug Metab 2: 339-354

Kanai Y, Segawa H, Miyamoto K, Uchino H, Takeda E, Endou H (1998) Expression cloning and characterization of a transporter for large neutral amino acids activated by the heavy chain of 4F2 antigen (CD98). J Biol Chem 273: 23629-23632

Kim CH, Park KJ, Park JR, Kanai Y, Endou H, Park JC, Kim do K (2006) The RNA interference of amino acid transporter LAT1 inhibits the growth of KB human oral cancer cells. Anticancer Res 26: 2943-2948

Kim DK, Kanai Y, Choi HW, Tangtrongsup S, Chairoungdua A, Babu E, Tachampa K, Anzai N, Iribe Y, Endou H (2002) Characterization of the system L amino acid transporter in T24 human bladder carcinoma cells. Biochim Biophys Acta 1565: $112-122$

Kobayashi H, Ishii Y, Takayama T (2005) Expression of L-type amino acid transporter 1 (LAT1) in esophageal carcinoma. J Surg Oncol 90: 233-238

Martin B, Paesmans M, Mascaux C, Berghmans T, Lothaire P, Meert AP, Lafitte JJ, Sculier JP (2004) Ki-67 expression and patients survival in lung cancer: systematic review of the literature with meta-analysis. $\mathrm{Br} J$ Cancer 91: $2018-2025$

Matsuo H, Tsukada S, Nakata T, Chairoungdua A, Kim DK, Cha SH, Inatomi J, Yorifuji H, Fukuda J, Endou H, Kanai Y (2000) Expression of a system L neutral amino acid transporter at the blood-brain barrier. Neuroreport 11: $3507-3511$

McGivan JD, Pastor-Anglada M (1994) Regulatory and molecular aspects of mammalian amino acid transport. Biochem J 299: $321-334$

Mountain CF (1997) Revision in the International System for staging lung cancer. Chest 11: $1710-1717$ 
Nakanishi K, Matsuo H, Kanai Y, Endou H, Hiroi S, Tominaga S, Mukai M, Ikeda E, Ozeki Y, Aida S, Kawai T (2006) LAT1 expression in normal lung and in atypical adenomatous hyperplasia and adenocarcinoma of the lung. Virchows Arch 448: $142-150$

Nawashiro H, Otani N, Shinomiya N, Fukui S, Ooigawa H, Shima K, Matsuo H, Kanai Y, Endou H (2006) L-type amino acid transporter 1 as a potential molecular target in human astrocytic tumors. Int J Cancer 119: $484-492$

Ohkame H, Masuda H, Ishii Y, Kanai Y (2001) Expression of L-type amino acid transporter 1 (LAT1) and 4F2 heavy chain (4F2hc) in liver tumor lesions of rat models. J Surg Oncol 78: 265-271; discussion 271-272

Olaussen KA, Dunant A, Fouret P, Brambilla E, Andre F, Haddad V, Taranchon E, Filipits M, Pirker R, Popper HH, Stahel R, Sabatier L, Pignon JP, Tursz T, Chevalier TL, Soria JC (2006) DNA repair by ERCC1 in non-small cell lung cancer and cisplatin-based adjuvant chemotherapy. New Engl J Med 355: 983 -991

Oriuchi N, Higuchi T, Ishikita T, Miyakubo M, Hanaoka H, Iida Y, Endo K (2006) Present role and future prospect of positron emission tomography in clinical oncology. Cancer Sci 97: 1291-1297

Oxender DL, Christensen HN (1962) Evidence for two types of mediation of neutral amino acid transport in Ehrlich cells. Nature 197: 765-767
Shottenfeld D (1996) Epidemiology of Lung Cancer. Philadelphia, PA: Lippincott-Raven

Tamai S, Masuda H, Ishii Y, Suzuki S, Kanai Y, Endou H (2001) Expression of L-type amino acid transporter 1 in a rat model of liver metastasis: positive correlation with tumor size. Cancer Detect Prev 25: $439-445$

Tomiyoshi K, Amed K, Muhammad S, Higuchi T, Inoue T, Endo K, Yang D (1997) Synthesis of new fluorine-18 labeled amino acid radiopharmaceutical: L-F-alpha-methyl tyrosine using separation and purification system. Nucl Med Commun 18: 169-175

Uchino H, Kanai Y, Kim DK, Wempe MF, Chairoungdua A, Morimoto E, Anders MW, Endou H (2002) Transport of amino acid-related compounds mediated by L-type amino acid transporter 1 (LAT1): Insights into the mechanisms of substrate recognition. Mol Pharmacol 61: $729-737$

Yanagida O, Kanai Y, Chairoungdua A, Kim DK, Segawa H, Nii T, Cha SH, Matsuo H, Fukushima J, Fukasawa Y, Tani Y, Taketani Y, Uchino H, Kim JY, Inatomi J, Okayasu I, Miyamoto K, Takeda E, Goya T, Endou H (2001) Human L-type amino acid transporter 1 (LAT 1): characterization of function and expression in tumor cell lines. Biochim Biophys Acta 1514: $291-302$ 